\title{
AVALIAÇÃO DA CONDIÇÃO AMILOLÍTICA DE BACTÉRIAS LÁTICAS EM MEIOS COM BATATA NA PRODUÇÃO DE ÁCIDO LÁTICO
}

\author{
M. L. F. ALVES ${ }^{1}$, R. S. LEAL ${ }^{1}$, C. A. REIS ${ }^{1}$, O.L.M. BERNAL ${ }^{1}$, J. G. L. F. ALVES ${ }^{1}$ \\ ${ }^{1}$ Universidade Federal de Lavras, Departamento de Ciência dos Alimentos \\ E-mail para contato: mariliana_luiza@hotmail.com,jlembi@dca.ufla.br
}

\begin{abstract}
RESUMO - O ácido lático (AL) é um ácido orgânico que pode ser obtido por homofermentação de bactérias láticas (BAL). Pesquisadores vêm relatando a existência de espécies capazes de converter amido diretamente em AL, dispensando o processo de hidrólise, as chamadas BAL amilolíticas. No Brasil, o cultivo de batata possui grande importância econômica, contudo apresenta perdas significativas em sua cadeia produtiva. Assim, esse trabalho teve por objetivo testar 5 espécies de BAL (Enterococcu durans, E. faecalis, Lactobacillus plantarum, L. rhamnosus e Streptococcus mutans), utilizando meios de fermentação à base de batata para avaliar a produção de AL. Os meios continham $33 \%(\mathrm{~m} / \mathrm{m})$ de polpa de batata e foram enriquecidos ou não com $5 \%(\mathrm{~m} / \mathrm{v})$ de extrato de levedura (EL). As fermentações foram conduzidas em erlenmeyers dentro de estufa BOD sem agitação $\left(37^{\circ} \mathrm{C} / 96 \mathrm{~h}\right)$. A quantificação de AL foi determinada por CLAE. Foram estudadas ainda a variação do $\mathrm{pH}$ e da acidez titulável ao longo da fermentação. Dentre os meios avaliados, as maiores produtividades foram observadas em meios enriquecidos com EL. S. mutans foi quem apresentou maior produção de $\operatorname{AL}(2,06 \mathrm{~g} / \mathrm{L})$, com produtividade de 0,02 g. $\mathrm{L}^{-1} \cdot \mathrm{h}^{-1}$.
\end{abstract}

\section{INTRODUÇÃO}

As bactérias do ácido lático (BAL) são microrganismos amplamente conhecidos e de extrema importância comercial que obtém energia através da fermentação de açúcares e possui o ácido lático (AL) como produto final da via homofermentativa (Salminen et al., 2004). Nos últimos anos, diversas pesquisas vêm relatando a existência de BAL capazes de converter amido diretamente em AL, dispensando o processo de hidrólise, são as bactérias láticas amilolíticas (Haydersah et al., 2012; Shibata et al., 2007; Wee et al., 2008). A obtenção de AL por via fermentativa apresenta vantagens em relação à síntese química, já que pode-se empregar nesse processo matérias-primas de baixo custo, subprodutos ou resíduos industriais, atendendo assim à crescente preocupação da sociedade a sustentabilidade do meio ambiente (John et al., 2007).

Durante a fermentação microbiana é possível agregar fatores que aumentem a produção do AL. Atualmente, a substituição eficiente da fonte de carbono empregada e de alto valor agregado por excedentes e resíduos da agroindústria e da indústria de alimentos, tal como o 
amido, facilmente disponível a partir da batata e outras biomassas, representa uma atraente alternativa ao processo (John et al., 2007). No Brasil, o Estado de Minas Gerais é o maior produtor nacional do tubérculo (Instituto Brasileiro de Geografia e Estatística, 2013) e tem grande parte de sua produção anual descartada em virtude das exigências dos consumidores brasileiros em relação à aparência externo do tubérculo (Tavares, 2009). Assim, esta pesquisa teve como objetivo investigar a capacidade amilolítica de diferentes linhagens de BAL e estudar a influência da adição de extrato de levedura nos meios de fermentação a base de polpa de batata, avaliando a cinética da fermentação e a produtividade do processo.

\section{MATERIAS E MÉTODOS}

\subsection{Obtenção e manutenção dos Microrganismos}

Os microrganismos utilizados foram cedidos pela Fundação Oswaldo Cruz (FioCruz/RJ) e de acordo com o acervo disponível foram selecionadas as espécies de BAL já relatadas como amilolíticas: Enterococcus durans (ATCC 6056), E. faecalis (ATCC 29212), Lactobacillus plantarum (ATCC 10012), L. rhamnosus (ATCC 9595) e Streptococcus mutans (ATCC 25175). Os microrganismos liofilizados foram ativados a $37^{\circ} \mathrm{C} / 48 \mathrm{~h}$ em caldo MRS (Man, Rogosa e Sharpe, Himédia $\left.{ }^{\circledR}\right)$ estéril $\left(121^{\circ} \mathrm{C} / 15 \mathrm{~min}\right)$, propagados e armazenados em cultura estoque de glicerol.

\subsection{Preparo do Inóculo e do Meio de Fermentação}

Com base na correlação absorbância e número de células viáveis, estabelecida por meio das curvas de crescimento, determinou-se os volumes de inóculo a ser transferido para o meio de fermentação: $1 \%$ v/v (L. plantarum e L. rhamnosus) e $10 \%$ v/v (E. durans, E. faecalis e $S$. mutans) ambos correspondente a uma contagem inicial entre $10^{7}$ e $10^{8}$ UFC.mL ${ }^{-1}$.

Batatas da espécie Solanum tuberosum ssp. tuberosum, cultivar Ágata, foram lavadas, secas, descascadas, picadas e trituradas em liquidificador industrial (5 min). Em sequência, a polpa foi armazenada em sacos hermeticamente fechados $(1 \mathrm{~kg} / \mathrm{saco})$ em temperatura de congelamento para posterior utilização. Para o preparo do meio, $330 \mathrm{~g}$ da polpa de batata descongelada foi acrescida de $670 \mathrm{~mL}$ de água destilada. Essa mistura foi acrescida ou não de $5 \%(\mathrm{~m} / \mathrm{v})$ de extrato de levedura (EL) e homogeneizada. $\mathrm{O} \mathrm{pH}$ foi ajustado para a faixa ótima de atuação das BAL, entre 5 e 7 (Salminen et al., 2004) e o meio foi então esterilizado (121 ${ }^{\circ} \mathrm{C} / 15 \mathrm{~min}$ ), arrefecido e inoculado (1 ou $10 \%$ de inóculo). As fermentações foram conduzidas em estufa BOD sem agitação $\left(37{ }^{\circ} \mathrm{C} / 96 \mathrm{~h}\right)$ dentro de erlenmeyers vedados com algodão. Foram retiradas do mosto aproximadamente $15 \mathrm{~mL}$ de amostra a cada $12 \mathrm{~h}$. As amostras foram centrifugadas ( $2260 \mathrm{~g} / 30 \mathrm{~min}$ ), o sedimentado foi descartado e o sobrenadante foi congelado e armazenado para análises posteriores. Todos os processos fermentativos foram realizados em triplicata.

\subsection{Avaliação da Capacidade Amilolítica}

A investigação da capacidade amilolítica dos microrganismos empregados neste estudo, teve como base a avaliação do desempenho dos mesmos em produzir AL em meio de polpa de batata não hidrolisada. Também foram considerados os resultados das demais análises. 


\subsection{Metodologia Analítica}

Caracterização da matéria-prima: A umidade e a composição centesimal da polpa de batata foram determinadas conforme a AOAC International (2012) e o Instituto Adolfo Lutz (2008), e o teor de amido seguiu a metodologia de Somogyi modificado por Nelson (1944).

Determinação do $\mathrm{pH}$ e acidez titulável: $\mathrm{O} \mathrm{pH}$ das amostras foram medidos com auxílio de potenciômetro digital de bancada. A acidez titulável foi determinada conforme a AOAC International, (2012) e o ponto de viragem da titulação foi conferido para pH próximo a 8,3.

Quantificação e produtividade de AL: As amostras foram filtradas através de filtros de seringa $(0,22 \mu \mathrm{m}$ de porosidade e $25 \mathrm{~mm}$ de diâmetro) e diluídas com água deionizada antes da análise. Foi utilizado cromatógrafo (Shimadzu) equipado com detector de condutividade (CDD-6A), polaridade +, uma pré-coluna SHIM-PACK SPR-H $(\mathrm{G})(50 \mathrm{~mm} \times 7.8 \mathrm{~mm})$ e duas colunas em série SHIM-PACK SPR-H $(250 \mathrm{~mm} \times 7.8 \mathrm{~mm})$. A fase móvel foi uma mistura de $16 \mathrm{mM}$ de Bis-Tris, $4 \mathrm{mM}$ de ácido p-tolueno sulfônico e $100 \mu \mathrm{M}$ de EDTA; com fluxo de 0,8 $\mathrm{mL} / \mathrm{min}$. O volume injetado da amostra foi de $20 \mu \mathrm{L}$ e a temperatura de injeção $45^{\circ} \mathrm{C}$. A quantificação do AL foi determinada pela comparação dos tempos de retenção dos picos e curva analítica de $\mathrm{AL}\left(\right.$ Sigma $\left.^{\circledR}\right)$. A produtividade do processo se deu pela relação de $\mathrm{AL}$ produzido e o tempo de fermentação (Oliveira et al., 2009).

Contagem de células viáveis: Utilizou-se plaqueamento em profundidade ("pour plate"). As amostras foram diluídas decimalmente em água peptonada $0,1 \%(\mathrm{~m} / \mathrm{v})$, distribuída em placas de petri e homogeneizada no meio de cultura ágar MRS (Himédia ${ }^{\circledR}$ ). As placas foram incubadas a $37{ }^{\circ} \mathrm{C} / 72 \mathrm{~h}$ (Tebaldi et al., 2007). Todas as análises foram realizadas em triplicata e os seus resultados expressos pela média desses valores.

\section{RESULTADOS E DISCUSSÃO}

A composição química da polpa de batata utilizada nesse estudo para amido, cinzas, fibra, lipídeos, proteína e umidade foi de 8,$17 ; 0,72 ; 0,6 ; 0,14 ; 2,25$ e $85,65 \% \mathrm{~m} / \mathrm{m}$, respectivamente, e é próxima aos valores relatados por outros autores (Evangelista et al., 2011; Núcleo de Estudos e Pesquisas em Alimentos, 2006).

\subsection{Estudo Cinético do pH e Acidez das Fermentações}

Todos os meios fermentativos testados apresentaram $\mathrm{pH}$ inicial dentro do intervalo considerado ótimo para atividade metabólica dos microrganismos, entre 5 e 7 (Salminen et $a l .$, 2004), proporcionando assim, condições adequadas para a produção de AL.

Avaliando os meios fermentativos sem EL (Figura 1A e 1B), observa-se que entre as espécies estudadas, L. rhamnosus manteve o maior $\mathrm{pH}$ durante toda a fermentação, com $\mathrm{pH}$ final $(5,29)$ próximo daquele apresentado inicialmente $(5,56)$. $S$. mutans apresentou menor $\mathrm{pH}$ final $(4,28)$, Figura 1A. A cinética da acidez (Figura 1B) corroborou com o comportamento do $\mathrm{pH}$, havendo maior produção de ácidos nas 12 primeiras horas de fermentação e, consequente diminuição de $\mathrm{pH}$ (Figura 1A) nesse mesmo período. A menor produção de ácidos se deu por L. rhamnosus $(0,03 \%)$ e a maior por $S$. mutans $(1,92 \%)$. 

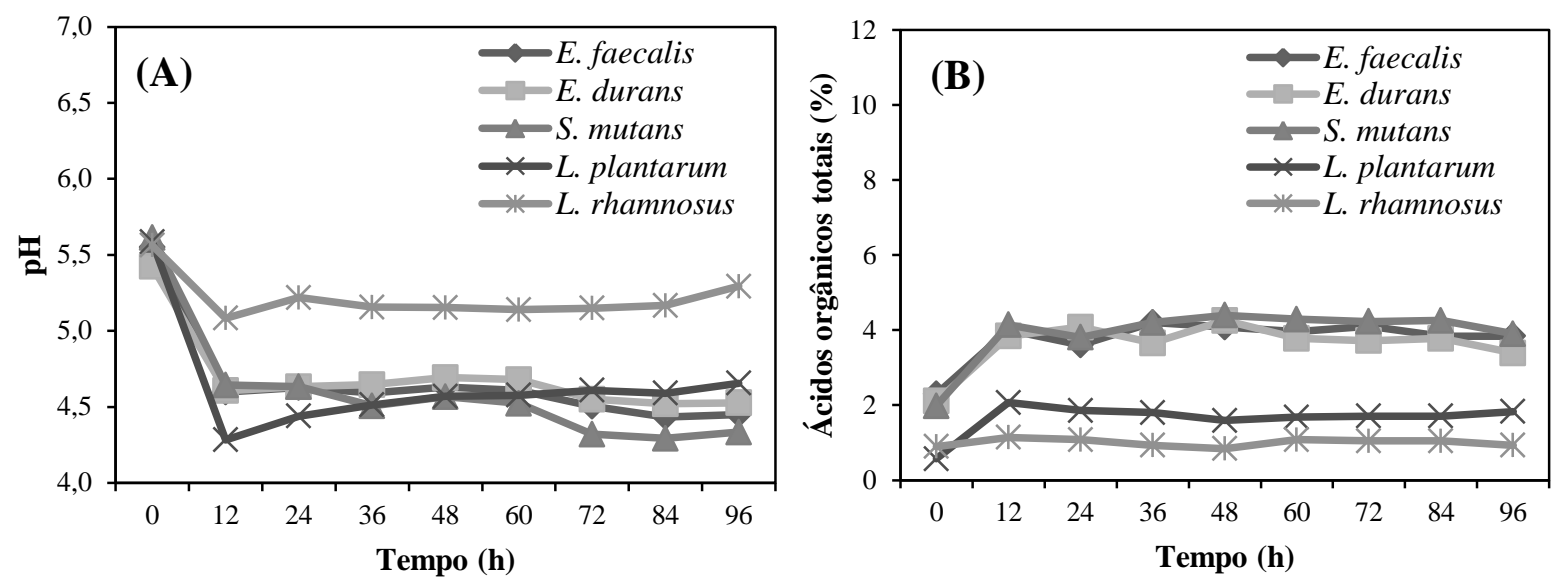

Figura 1 - Cinética do pH (A) e da produção de ácidos orgânicos totais (B) em meios fermentativos sem extrato de levedura

No mosto com de EL (Figura 2) as espécies do gênero Lactobacillus também apresentaram estabilização de pH após 12 h de fermentação e E. durans apenas 72 h depois. As demais espécies tiveram redução gradativa do $\mathrm{pH}$ no decorrer do processo. $\mathrm{O} \mathrm{pH}$ final das BAL avaliadas manteve-se entre 4,5 e 4,75 (Figura 2A). A adição de EL no mosto aumentou consideravelmente a produção de ácidos orgânicos totais no processo fermentativo (acidez final menos acidez inicial), sendo a maior produção obtida por L. plantarum $(3,90 \%)$ e $L$. rhamnosus (2,90\%), em meios com EL (Figura 2B). Estes mesmos microrganismos produziram $1,26 \%$ e $0,03 \%$, respectivamente, quando o meio não foi suplementado (Figura 1B).
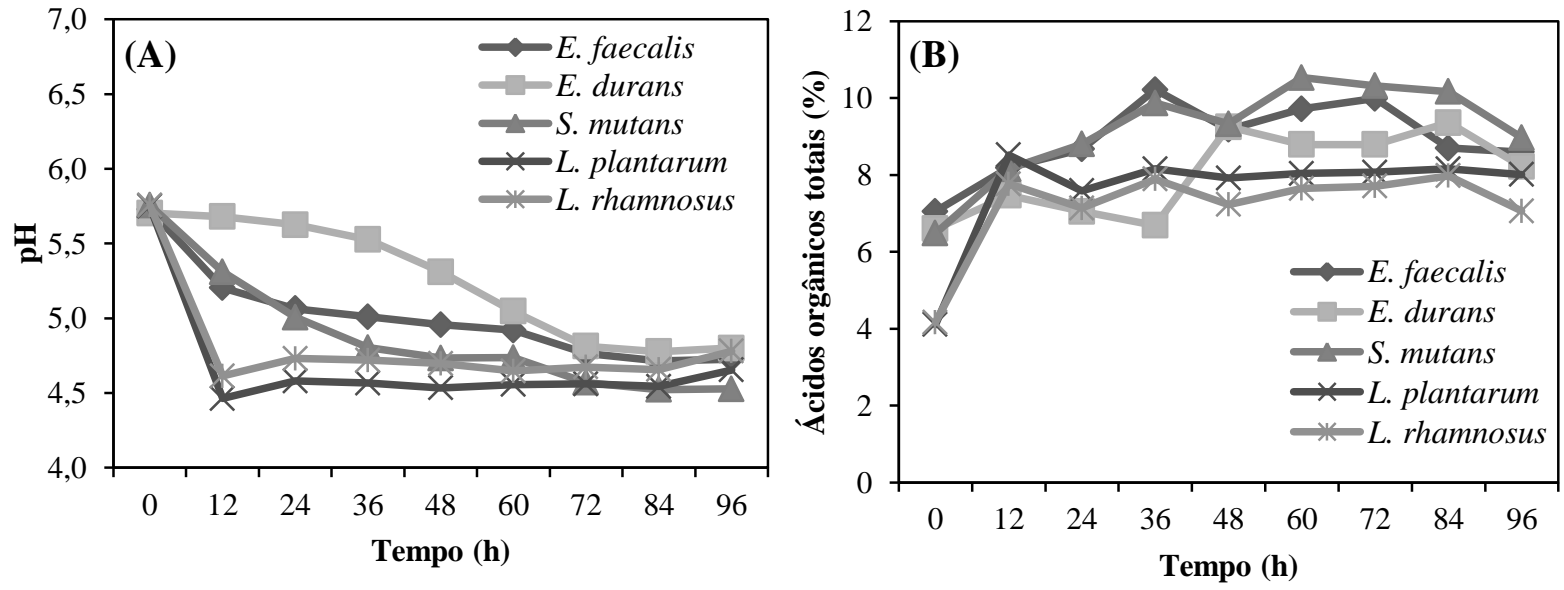

Figura 2 - Cinética do pH (A) e da produção de ácidos orgânicos totais (B) em meios fermentativos com extrato de levedura

As BAL são conhecidas por suportarem elevada acidez no meio fermentativo (Martinez et al., 2013). Contudo, pesquisadores concluíram que o controle do $\mathrm{pH}$ nesse processo pode aumentar, significativamente, a produção de AL (Abdel-Rahman et al., 2013; Moon et al., 2012) uma vez que atividade catalítica das enzimas e a atividade metabólica dos microrganismos dependem do $\mathrm{pH}$ intra e extra celular (Mozzi et al., 2010). Neste contexto, alguns métodos de controle de $\mathrm{pH}$ são relatados, como a adição de agentes neutralizantes 
(Djukić-Vuković et al., 2012). Porém, estes podem afetar a produção de AL pelo aumento dos custos de purificação, causando consideráveis problemas ambientais (Martinez et al., 2013).

\subsection{Produção de ácido lático}

De acordo com as análises de quantificação de AL, os meios com EL foram os que apresentaram maior produção do metabólito de interesse (Figura 3). Sendo que aquele fermentado por $S$. mutans foi quem atingiu a maior concentração final de AL $(2,06 \mathrm{~g} / \mathrm{L})$.

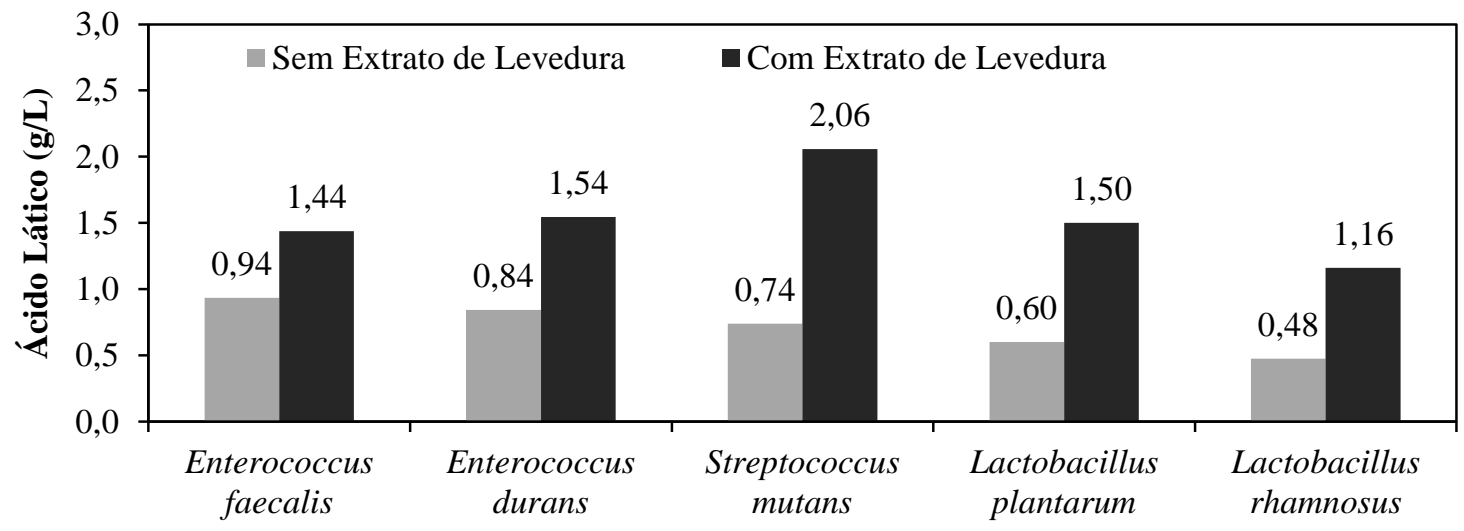

Figura 3 - Produção de ácido lático por bactérias láticas em mosto de polpa de batata

Os resultados obtidos neste trabalho elucidam a importância da suplementação do meio de fermentação com uma fonte de nitrogênio quando se visa à maior produção de AL. Conforme a Figura 3, a adição de EL no meio de fermentação proporcionou o aumento de 0,74 para 2,06 g/L na produção de AL por S. mutans. Segundo Mi-Young et al., (2003), o EL satisfaz as exigências nutricionais, o enriquecimento exerce notadamente efeito positivo na produção de AL pelo aumento no consumo de AR, uma vez que é de conhecimento prévio que esses microrganismos obtêm energia por meio da fermentação de açúcares.

Assim como Naveena et al. (2011), vários outros autores já relataram a importância do enriquecimento do meio de fermentação com uma fonte de nitrogênio, quando se utilizam BAL no processo, independente do substrato empregado. Oliveira et al. (2009) duplicaram a produção de AL ao enriquecer o meio de melaço de cana com $2 \%$ de EL e Guilherme et al. (2009) aumentaram a produção de 9,01 g/L para 15,48 g/L de $\mathrm{AL}$ ao enriquecer o meio de fermentação de xarope de caju com $8 \%$ de EL. Chauhan et al. (2007) também enriqueceram o meio fermentativo com EL e observaram um aumento de 15,1 g/L de AL utilizando suco de tamareira.

\subsection{Capacidade Amilolítica das Bactérias Láticas}

Ao investigar a capacidade de conversão direta de amido em AL pelas espécies de BAL, observou-se que a produtividade máxima obtida foi de $0,02 \mathrm{~g} \cdot \mathrm{L}^{-1} \cdot \mathrm{h}^{-1}$, com produção máxima de 2,06 g/L de AL por S. mutans (Figura 5). Narita et al. (2004) visando a avaliar a capacidade amilolítica de $S$. bovis utilizando como substrato fermentativo glicose e amido (20 g/L), produziram 14,73 g/L de AL após 100 h de fermentação em biorreator com controle de $\mathrm{pH}$. Estudos anteriores em meio fermentativos de batata e isolados amilolíticos do gênero 
Lactobacillus, produziram 4,2 g/L de AL (Xiaodong et al., 1997), o mesmo meio também foi utilizado por Shibata et al. (2007) ao produzirem 14,3 g/L de AL e produtividade de 0,545 $\mathrm{g} . \mathrm{L}^{-1} \cdot \mathrm{h}^{-1}$ com espécie amilolítica do gênero Enterococcus.

Apesar dos gêneros aqui investigados já terem sido relatados como amilolíticos (Narita et al., 2004; Shibata et al., 2007), sabe-se que essa característica pode ser alterada conforme o substrato fermentativo e as condições de fermentação (Reddy et al., 2008). Bomrungnok et al. (2012), concluíram que L. plantarum SW14 tinha potencial para a produção direta de AL a partir do amido de mandioca, quando estudou a fermentação de modo contínuo com alta densidade celular e elevada taxa de diluição, observando produtividade de $\mathrm{AL}$ de 8,0 g. $\mathrm{L}^{-1} \mathrm{~h}^{-1}$. Mesmo utilizando um produto amiláceo como substrato fermentativo, as condições de fermentação apresentadas pelos autores diferem daquelas utilizadas neste estudo, principalmente no modo de fermentação, já que o presente estudo utilizou a batelada simples.

\subsection{Viabilidade Celular}

Em todos os meios fermentativos, os microrganismos mantiveram a contagem na ordem de $10^{7}$ e $10^{8}$ UFC. $\mathrm{ml}^{-1}$ ao final do processo, mesmo com os baixos valores de $\mathrm{pH}$ ao longo da fermentação. Tal ocorrência se deve a alta tolerância das BAL as condições ácidas, $\mathrm{pH}<5$ (Martinez et al., 2013), conferindo, assim, uma vantagem significativa em relação aos demais microrganismos. $\mathrm{O}$ uso de espécies que toleram baixo $\mathrm{pH}$ é importante, pois minimizam o uso de agentes tamponantes, reduzindo os custos e os problemas de poluição, além de facilitar os processos de recuperação do AL (John; Nampoothiri, 2008).

\section{CONCLUSÃO}

$\mathrm{Na}$ literatura não é mencionado um padrão que determina quantidade de $\mathrm{AL}$ a ser produzido por conversão direta do amido para que a espécie seja considerada amilolítica. As concentrações finais de ácido lático nos meios de fermentação foram baixas, indicando reduzidas capacidades amilolíticas nas condições testadas, sendo que a bactéria $S$. mutans foi quem apresentou maior produção de AL (2,06 g/L), com produtividade de $0,02 \mathrm{~g} \cdot \mathrm{L}^{-1} \cdot \mathrm{h}^{-1}$, em meio adicionado de extrato de levedura.

\section{RERÊNCIAS}

ABDEL-RAHMAN, M. A.; TASHIRO, Y.; SONOMOTO, K. Recent advances in lactic acid production by microbial fermentation processes. Biotechnol Adv, v. 31, n. 6, p. 877-902, 2013.

AOAC INTERNATIONAL. Official Methods of Analysis of AOAC International. 19. th. ed. Chicago: Pharmaboocks, 2012.

SALMINEN, S.; VON WRIGHT, A.; OUWEHAND, A. Lactic acid bacteria microbiological and functional aspects. 3. ed. New York: Marcel Dekker, Inc., 2004.

BOMRUNGNOK, W. SONOMOTO, K.; PINITGLANG, S.;WONGWICHARN, A. Single step lactic acid production from cassava starch by Lactobacillus plantarum SW14 in continuous and continuous with high cell density. APCBEE Procedia, v. 2, p. 97-103, 2012. 
CHAUHAN, K.; TRIVEDI, U.; PATEL, K. C. Statistical screening of medium components by Plackett-Burman design for lactic acid production by Lactobacillus sp. KCP01 using date juice. Bioresour Technol, v. 98, n. 1, p. 98-103, 2007.

DJUKIĆ-VUKOVI Ć, A. P. et al. Effect of different fermentation parameters on L -lactic acid production from liquid distillery stillage. Food Chem, v. 134, p. 1038-1043, 2012.

EVANGELISTA, R. M. et al. Qualidade nutricional e esverdeamento pós-colheita de tubérculos de cultivares de batata. Pesq Agropecuária Bras, v. 46, n. 8, p. 953-960, 2011.

GUILHERME, A. A.; PINTO, G. A. S.; RODRIGUES, S. Avaliação da produção de ácido lático por Leuconostoc mesenteroides $\mathrm{B} 512 \mathrm{~F}$ em xarope de caju. Ciência e Tecnol de Aliment, v. 29, n. 4, p. 738-747, 2009.

HAYDERSAH, J. et al. Fermentation by amylolytic lactic acid bacteria and consequences for starch digestibility of plantain, breadfruit, and sweet potato flours. $J$ Food Sci, v. 77, n. 8, p. 466-472, 2012.

INSTITUTO ADOLFO LUTZ. Métodos físico-químicos para análise de alimentos. 4. ed. São Paulo: Instituto Adolfo Lutz, 2008.

JOHN, R. P.; NAMPOOTHIRI, K. M. Strain improvement of Lactobacillus delbrueckii using nitrous acid mutation for l-lactic acid production. World J Microbiol Biotechnol, v. 24, n. 12, p. 3105-3109, 2008.

JOHN, R. P.; NAMPOOTHIRI, K. M.; PANDEY, A. Fermentative production of lactic acid from biomass: an overview on process developments and future perspectives. Appl Microbiol Biotechnol, v. 74, n. 3, p. 524-534, 2007.

INSTITUTO BRASILEIRO DE GEOGRAFIA E ESTATÍSTICA. Batata. São Paulo:IBGE, 2013. Disponível em: <http://www.agricultura.mg.gov.br/ index.php?option =com_content $\&$ view $=$ article \&id=1361\&Itemid=29>. Acesso em: 20 out. 2013.

MARTINEZ, F. A. C. et al. Lactic acid properties, applications and production: A review. Trends Food Sci Technol., v. 30, n. 1, p. 70-83, 2013.

MI-YOUNG, H. et al. Kinetics analysis of growth and lactic acid production in $\mathrm{pH}$-controlled batch cultures of Lactobacillus casei KH-1 using yeast Extract / corn Steep liquor / glucose medium. J Biosci Bioeng, v. 96, n. 2, p. 134-140, 2003.

MOON, S.; WEE, Y.; CHOI, G. A novel lactic acid bacterium for the production of high purity L-lactic acid, Lactobacillus paracasei subsp. paracasei CHB2121. J Biosci Bioeng, v. 114, n. 2, p. 155-159, 2012.

MOZZI, F.; RAYA, R. R.; VIGNOLO, G. M. Biotechnology of lactic acid bacteria: novel applicattions. Ames: Blackwell, 2010. p. 414

NARITA, J.; NAKAHARA, S.; FUKUDA, H. Efficient production of L (+) lactic acid from raw starch by Streptococcus bovis 148. J Biosci Bioeng, v. 97, n. 6, p. 423-425, 2004.

NAVEENA, B. J. et al. Single step fermentation of starch to L(+) lactic acid by Lactobacillus amylophilus GV6 in SSF using inexpensive nitrogen sources to replace peptone and yeast extract: optimization by RSM. Process Biochemistry, v. 41, n. 2, p. 465-472, 2011.

NELSON, N. A photometric adaptation of the Somogyi method for the determination of glucose. J Biol Chem, v. 153, p. 375-380, 1944. 
NÚCLEO DE ESTUDOS E PESQUISAS EM ALIMENTOS. Tabela brasileira de composição de alimentos. 2. ed. Campinas: NEPA, 2006.

OLIVEIRA, R. F. et al. Produção fermentativa de ácido lático a partir do melaço da cana-deaçúcar por Lactobacillus casei. Brazilian J Food Technol, v. 7, p. 34-40, 2009.

REDDY, G. et al. Amylolytic bacterial lactic acid fermentation - A review. Biotechnol. $A d v$. , v. 26, p. 22-34, 2008.

SHIBATA, K. et al. Direct L-lactic acid fermentation with sago starch by a novel amylolytic lactic acid bacterium, Enterococcus faecium. Enzyme Microbial Technol, v. 41, p. 149-155, 2007.

TAVARES, V. B. Silagens de capim-elefante aditivadas com raspa de batata diversa na alimentação de bovinos leiteiros. Lavras: Universidade Federal de Lavras, 2009.

TEBALDI, V. M. R. et al. Avaliação microbiológica de bebidas lácteas fermentadas adquiridas no comércio varejista do sul de Minas Gerais. Ciência e Tecnol de Aliment, v. 31, n. 4, p. 1085-1088, 2007.

WEE, Y.; REDDY, L. V. A.; RYU, H. Fermentative production of L (+) lactic acid from starch hydrolyzate and corn steep liquor as inexpensive nutrients by batch culture of Enterococcus faecalis RKY1. J Chem Technol Biotecnol, v. 83, p. 1387-1393, 2008.

XIAODONG, W.; XUAN, G.; RAKSHIT, S. K. Direct fermentative production of lactic acid on cassava and other starch substrates. Biotechnol, v. 19, n. 9, p. 841-843, 1997.

\section{AGRADECIMENTOS}

A FAPEMIG pelo financiamento e auxílio para participação no evento, à CAPES pela bolsa de Mestrado e à Fundação Oswaldo Cruz/RJ pela doação dos microrganismos. 